\title{
Glucagon-Like Peptide-1 Modulates Cholesterol Homeostasis by Suppressing the miR-19b-Induced Downregulation of ABCA1
}

\author{
Yue Yao ${ }^{\mathrm{a}, \mathrm{c}}$ Qiang Lia Wei Wang ${ }^{\mathrm{a}}$ Jinchao Zhang ${ }^{\mathrm{a}}$ Ping Gao ${ }^{\mathrm{a}}$ Yi Xub,c \\ aDepartment of Endocrinology and Metabolism, Second Affiliated Hospital of Harbin Medical \\ University, Harbin, bDepartment of Hepatopancreatobiliary Surgery, Second Affiliated Hospital of \\ Harbin Medical University, Harbin, 'The Key Laboratory of Myocardial Ischemia, Harbin Medical \\ University, Ministry of Education, Harbin, China
}

\section{Key Words}

Glucagon-like peptide-1 - Cholesterol homeostasis - ATP-binding cassette transporter A1 • miR-19b

\begin{abstract}
Background/Aims: Abnormal regulation of cholesterol homeostasis is associated with type 2 diabetes mellitus (T2DM) and multiple other diseases. Glucagon-like peptide-1 (GLP-1) has unique effects on modulating hepatic lipid metabolism. However, the mechanism behind these is largely unknown. The aim of this study was to investigate the effects of GLP-1 on cholesterol-induced lipotoxicity in hepatocytes and examine the underlying mechanisms. Methods: Cell viability was determined by CCK-8. Caspase-3 detection was used to assess the effects of GLP- 1 on cholesterol-induced apoptosis. TNF- $\alpha$ and IL- 6 as the inflammatory markers were measured by ELISA. The alterations of miR-19b and ATP-binding cassette transporter A1 (ABCA1) resulting from high-fat diet/cholesterol incubation or GLP-1 were detected by realtime PCR and western blot. Results: GLP-1 markedly up-regulated the expression of ABCA1 protein, but didn't affect peroxisome proliferator-activated receptor $\alpha$ (PPAR- $\alpha$ ) protein. The miR-19b levels were significantly down-regulated in GLP-1-treated groups. The inhibition and overexpression of miR-19b were established to explore the effects of a GLP-1-mediated alteration in miR-19b. Cholesterol transport assays revealed that treatment with GLP-1 alone or together with miR-19b inhibitor significantly enhanced ABCA1-dependent cholesterol efflux, resulting in reduced total cholesterol. Further, histological examination was used to detect lipid accumulation. Cholesterol significantly attenuated cell viability, promoted hepatic cell apoptosis, and facilitated lipid accumulation, and these effects could be reversed by GLP1. Conclusion: GLP-1 may affect cholesterol homeostasis by regulating the expression of miR-19b and ABCA1.




\section{Introduction}

Type 2 diabetes mellitus (T2DM) is a multifactorial metabolic disease characterized by insulin resistance. Dysregulation of lipid metabolism in liver cells is a main pathogenic risk factor for insulin resistance [1-3]. Hepatic cholesterol metabolism is an important process in the maintenance of total body cholesterol homeostasis. Cholesterol homeostasis is critical for normal cell function, and its improper distribution or metabolism can induce serious consequences for cells and organisms [4, 5]. Because of this, cells have developed complex mechanisms to regulate the abundance and distribution of sterols cholesterol cells.

ATP-binding cassette transporter A1 (ABCA1) is an integral membrane protein, which plays an essential role in mediating cholesterol efflux to apolipoprotein A-I, as a major housekeeping mechanism for cellular cholesterol homeostasis [6, 7]. Cholesterol efflux via ABCA1 is a gatekeeper for cells to eliminate excess cholesterol and prevent cellular cholesterol accumulation [8-11]. Several epidemiological studies have revealed that inappropriate cholesterol accumulation leads to nonalcoholic fatty liver disease, obesity, T2DM, atherosclerosis, and even increases the risk of multiple types of cancer $[5,12,13]$. The activity of the ABCA1 pathway is elaborately modulated, and an increase in ABCA1 activity will prevent cholesterol accumulation in cells $[6,7]$.

Glucagon-like peptide 1 (GLP-1) as a novel anti-diabetic drug with multiple effects, not only has hypoglycaemic effects, but also relieves lipotoxicity at the cellular level $[14,15,16]$. GLP-1 has unique abilities to modulate lipid metabolism by affecting lipid assimilation and transport, fat formation and decomposition, hepatic lipid metabolism and reverse cholesterol transport $[17,18,19]$. The apolipoprotein A-I gene, encoding the primary anti-atherogenic factor in high-density lipoprotein (HDL) particles, is increased in both GLP-1 and exendin4-treated HepG2 cells, and this phenomenon is accompanied by similar changes in the expression of ABCA1 [20]. Research has shown that GLP-1 and exendin-4 promote ABCA1 expression in multiple cell lines, including glomerular endothelial cells, pancreatic $\beta$ cells and adipocytes. GLP-1R-mediated signalling pathways (e.g., $\mathrm{Ca}^{2+} /$ calmodulin-dependent protein kinase, cAMP/PKA, ERK1/2 and PI3K/AKT) are involved in cholesterol efflux by regulating ABCA1 expression [21-23]. However, the mechanism by which GLP-1 improves cholesterol homeostasis via ABCA1 in hepatic cells remains unclear.

Researches shows that ABCA1 is comprehensively regulated by intracellular microRNAs (miRNAs) [24, 25]. These non-coding RNAs have been identified as important posttranscriptional regulators of cholesterol homeostasis. Several miRNAs, such as miR-33, miR-122, miR-370, miR-378, miR-146b, miR-27 and miR-19b, show effects on ameliorating cholesterol homeostasis and fatty acid metabolism [5, 26, 27]. Circulating miR-19b is correlated with biomarkers of lipid metabolism [28]. It has been reported that miR-19b binds to the 3'-UTR of ABCA1 transporters, and this novel interaction has multiple potential roles in cholesterol metabolism [29]. In this context, this study investigates the efficacy of GLP-1 on improving hepatic cells cholesterol homeostasis through the miR-19b/ABCA1 interaction in vivo and in vitro.

\section{Materials and Methods}

\section{Animal experiments}

60 male SD rats 3 to 4 weeks old were purchased from the Experimental Animal Center of Second Affiliated Hospital of Harbin Medical University. After a 7-day adaptation period, rats were assigned to two dietary treatments in a completely randomized design, namely, a control diet and high-fat diet (D12108) (Research Diets Inc., New Brunswick, NJ). A total of 60 rats were fed the control diet (20 rats) and the high-fat diet (40 rats) for 16 weeks. At 4 weeks after raising, the rats in control diet group were randomly subdivided into two groups (10 rats per group): with or without daily subcutaneous injection of GLP-1 (20 $\mu \mathrm{g} / \mathrm{kg}$, Sigma, USA). Meanwhile, the rats in high-fat diet group were randomly subdivided into four groups (10 rats per group): high-fat diet alone (HFD), HFD+GLP-1 (HG), HFD+GLP-1+agomiR-19b (HG-Ago), and 


\section{Cellular Physiology Cell Physiol Biochem 2018;50:679-693 \begin{tabular}{l|l|l} 
and Biochemistry Published online: 12 October 2018 & $\begin{array}{l}\text { @ } 2018 \text { The Author(s). Published by S. Karger AG, Basel } \\
\text { www.karger.com/cpb }\end{array}$ \\
\hline
\end{tabular}}

Yao et al.: GLP-1 Suppresses miR-19b in Cholesterol Homeostasis

HFD+GLP-1+antagomiR-19b groups (HG-Ant). The rats from the HG-Ago group and HG-Ant group received tail vein injections of $80 \mathrm{mg} / \mathrm{kg}$ agomiR-19b/antagomiR-19b, on days 1-3 of every other week after starting the high-fat diet $[29,30]$. Rats were sacrificed by exsanguination after isoflurane anaesthesia. Serum and livers were frozen in liquid nitrogen instantly and stored at $-80^{\circ} \mathrm{C}$ for biochemical analysis, and aliquots of the livers were fixed for histological examination. The experiments were performed with the approval of the Animal Care and Use Committee of the Harbin Medical University of China according to the institutional guidelines for the use and care of laboratory animals [31].

\section{Cell culture and treatments}

Human HepG2 cells (a kind gift from the Harbin Medical University Cancer Institute) were cultured as previously described [32], in RPMI 1640 medium (HyClone, USA) supplemented with 10\% foetal bovine serum (GIBCO, USA), $100 \mathrm{IU} / \mathrm{ml}$ penicillin and $100 \mathrm{~g} / \mathrm{ml}$ streptomycin. The cells were cultured at $37{ }^{\circ} \mathrm{C}$ in a $5 \% \mathrm{CO}_{2}$ environment. The cells were cultured to $80 \%$ confluence, incubated with or without $5 \mathrm{mmol} / \mathrm{L}$ soluble cholesterol (Sigma, USA) medium (CHO) for $24 \mathrm{~h}$, and then maintained with or without $10 \mathrm{nmol} / \mathrm{L}$ GLP-1 (Sigma, USA) for the next 24h.

\section{Cytokine assays and measurement of serum biochemical parameters}

The serum concentrations of TNF- $\alpha$ (Huatan Institute of Biotechnology, Beijing, China) and IL-6 (Eiaab Science Co., Ltd, Wuhan, China) were measured by ELISA according to the manufacturer's instructions. Cholesterol was quantitated in HepG2 cells using a cholesterol quantitation kit (BioVision, CA, USA). In addition, aspartate aminotransferase (AST), alanine aminotransferase (ALT), triglyceride (TG), and total cholesterol (TC) concentrations were determined by an automatic biochemistry analyser (COBAS80000, c702, Swit).

\section{Measurement with the Cell Counting Kit-8 (CCK-8)}

This assay was to detect the viability of HepG2 cells. The cells were exposed to various concentrations of cholesterol (2.5, 5 and $10 \mathrm{mmol} / \mathrm{L})$, with or without $10 \mathrm{nmol} / \mathrm{L}$ GLP-1 for $24 \mathrm{~h}$. After replacing the RPMI 1640 medium, $10 \mu \mathrm{l}$ of CCK-8 reagent (Dojindo Molecular Technologies, Inc., Kumamoto, Japan) was added to each well, and the 96 -well plate was incubated in the dark at $37^{\circ} \mathrm{C}$ for $1.5 \mathrm{~h}$. The absorbance was measured at $450 \mathrm{~nm}$ in a microplate reader (Tecan). All the experiments were repeated three times.

\section{Caspase 3 analysis}

The expression of caspase- 3 is enhanced when cell apoptosis occurs and represents the degree of apoptosis to some extent. The activation level of caspase-3 was assayed to explore cholesterol-induced apoptosis using the caspase-3 Activity Kit (Solarbio, China). In short, after extraction of total cell proteins of each group, $10 \mu \mathrm{l}$ protein was incubated with $90 \mu \mathrm{l}$ of provided reaction buffer and $10 \mu \mathrm{l}$ Ac-DEVD-pNA (2 $\mathrm{mM}$ ) in 96 -well plates at $37^{\circ} \mathrm{C}$ for $2 \mathrm{~h}$. Afterwards, the reaction mixtures were measured at a wavelength of $405 \mathrm{~nm}$ in a microplate reader.

miRNA transfection

Oligonucleotide analogue and inhibitor which were chemically modified and synthesized were used to increase and decrease the expression of miR-19b in HepG2 cells. The microRNA-19b inhibitor, microRNA19b mimics, microRNA NC-FAM (GenePharm Co. Ltd, China) and lipofectamine ${ }^{\mathrm{TM}} 3000$ (Invitrogen, USA) were diluted in serum-free RPMI 1640 without antibiotics prior to being incubated at room temperature for 5 minutes. Next, diluted microRNAs were added to each tube of diluted Lipofectamine ${ }^{\mathrm{TM}} 3000$ Reagent (1:1 ratio) separately. The oligonucleotide-lipo complexes were added to the cells for $24 \mathrm{~h}$. Then cholesterol and GLP-1 were taken every other $24 \mathrm{~h}$ before further analysis. The sequences of mimics and inhibitors used are shown below: hsa-miR-19b mimics, sense 5'-UGUGCAAAUCCAUGCAAAACUGA-3'; antisense 5'-AGUUUUGCAUGGAUUUGCACAUU-3'; hsa-miR-19b inhibitor, 5'-UCAGUUUUGCAUGGAUUUGCACA-3'; microRNA NC-FAM, sense 5'-UUCUCCGAACGUGUCACGUTT-3'; antisense 5'-ACGUGACACGUUCGGAGAATT-3'. 


\section{Cellular Physiology Cell Physiol Biochem 2018;50:679-693 and Biochemistry Publishedor $\begin{aligned} & \text { DOI: 10.1159/000494235 } \\ & \text { (c) } 2018 \text { The Author(s). Published by S. Karger AG, Basel } \\ & \text { www.karger.com/cpb }\end{aligned}$

Table 1. Primers used for this study

\begin{tabular}{|c|c|c|}
\hline Parameter & Sprague-Dawley rats & HepG2 cels \\
\hline ABCA1 & $\begin{array}{l}\text { Forward: 5'-AATGGTCAATGGGAGGTTCA-3'; } \\
\text { Reverse: 5'-TGGACAGGCTTTAGGTCAGG-3' }\end{array}$ & $\begin{array}{l}\text { Forward: 5'-GACTAAAGCCATTTGTCTGTG-3'; } \\
\text { Reverse: 5'-CCAACAGAACTGTCACAGC-3' }\end{array}$ \\
\hline GAPDH & $\begin{array}{l}\text { Forward: 5'-GCCAGCCGAGCCACAT-3'; } \\
\text { Reverse: 5'-GGATCTCGCTCCTGGAAGAT -3' }\end{array}$ & $\begin{array}{l}\text { Forward: 5'-AACTTTGGCATTGTGGAAGG-3'; } \\
\text { Reverse: 5'-ACACATTGGGGGTAGGAACA-3' }\end{array}$ \\
\hline miR-19b & $\begin{array}{c}\text { RT primer: } \\
\text { GTCGTATCCAGTGCAGGGTCCGAGGTATTCGCACTGGATACGACCTGGAT } \\
\text { Forward: 5'-CGAGTTTTGCAGGTTGCATCCAG-3' } \\
\text { Reverse: 5'-ATCCAGTGCAGGGTCCGAGG -3' }\end{array}$ & $\begin{array}{c}\text { RT primer: } \\
\text { GTCGTATCCAGTGCAGGGTCCGAGGTATTCGCACTGGATACGACTCAGTT } \\
\text { Forward: 5'-CGCTGGTGTGCAAATCCATGCAA-3' } \\
\text { Reverse: 5' - ATCCAGTGCAGGGTCCGAGG -3' }\end{array}$ \\
\hline U6 & $\begin{array}{l}\text { RT primer: CGCTTCACGAATTTGCGTGTCAT } \\
\text { Forward: 5'-GCTTCGGCAGCACATATACTAAAAT-3' } \\
\text { Reverse: 5'-CGCTTCACGAATTTGCGTGTCAT-3' }\end{array}$ & $\begin{array}{c}\text { RT primer: } \\
\text { GTCGTATCCAGTGCAGGGTCCGAGGTATTCGCACTGGATACGACAAAATA } \\
\text { Forward: 5'-AGAGAAGATTAGCATGGCCCCTG-3' } \\
\text { Reverse: 5'-ATCCAGTGCAGGGTCCGAGG-3' }\end{array}$ \\
\hline
\end{tabular}

\section{RNA extraction and quantitative PCR}

Total RNA was extracted from rat livers and HepG2 cells using the Trizol reagent (Invitrogen, Waltham, USA). Reverse transcription was carried out using a Transcriptor First Strand cDNA Synthesis Kit (Roche, Germany). qRT-PCR reactions were detected using the Fast Start Universal SYBR Green Master (Roche, Germany) with CFX96 real time PCR detection system (Bio-Rad, USA). U6 small RNA and GAPDH were used as the reference gene. Each reaction was performed in triplicate according to the manufacturer's protocol, and the qRT-PCR results were calculated using the $2^{-\Delta \Delta C t}$ method [33]. All primer sequences are shown in Table 1.

\section{Protein extraction and western blotting}

For protein extraction, rat livers and HepG2 cells were lysed with $200 \mu$ of modified RIPA Lysis Buffer (Beyotime institute of Biotechnology, China) containing 1\% PMSF (Beyotime institute of Biotechnology, China) on ice. Splitted decomposition with ultrasonic wave for 30 second, then centrifugalized at $14,000 \mathrm{~g}$ at $4^{\circ} \mathrm{C}$ for $15 \mathrm{~min}$, the proteins were transferred to the fresh tube. The proteins were determined using the BCA method. Subsequently, proteins were fractionated by sodium dodecyl sulfate-polyacrylamide gel (SDSPAGE) electrophoresis and transferred to polyvinylidene fluoride (PVDF) membranes (GE Healthcare, USA). The membrane was incubated with primary antibodies to ABCA1 (1:500, ab18180), PPAR- $\alpha(1: 500, a b 8934)$ and GAPDH (1:10000, ab181602) (Abcam, USA). After the secondary antibody (Cell Signaling Technology, Danvers, USA) was probed for $2 \mathrm{~h}$, the blots were developed using an enhanced chemiluminescence kit (Beyotime institute of Biotechnology, China) and then visualized and photographed with the ChemiDoc imaging system (Tanon, Beijing, China).

\section{BODIPY-Cholesterol efflux assay (Cholesterol transport assay)}

A BODIPY-Cholesterol efflux assay was performed as previously described [23, 34]. In brief, HepG2 cells were incubated with $2.5 \mathrm{mM}$ of BODIPY-cholesterol in culture medium at $37^{\circ} \mathrm{C}$ for $2 \mathrm{~h}$. Cells were rinsed twice with Krebs-Ringer buffer and incubated at $37^{\circ} \mathrm{C}$ for $1 \mathrm{~h}$. The cell supernatant was centrifuged for 5 min at $6800 \mathrm{~g}$, and the BODIPY fluorescence intensity in the supernatants was measured using a TECAN GENios Pro Microplate Reader (Tecan US, Inc., Morrisville, NC, USA) at excitation $490 \pm 10 \mathrm{~nm}$ and emission $535 \pm 20 \mathrm{~nm}$.

\section{Oil red 0 staining}

For lipid droplets observation, the HepG2 cells were plated in 6-well plates. After stimulation with cholesterol and GLP-1 for $24 \mathrm{~h}$, each group was rinsed three times in PBS, fixed in 4\% paraformaldehyde for $30 \mathrm{~min}$, stained in freshly diluted oil red 0 for $15 \mathrm{~min}$, decolorized in 70\% ethanol solution for $15 \mathrm{sec}$, re-dyed in haematoxylin staining solution for $30 \mathrm{sec}$ and rinsed in PBS twice. Finally, the intracellular lipid droplets were observed and captured with an inverted microscope (Leica, Wetzlar, Germany).

\section{Haematoxylin and eosin (HE) staining}

The liver specimens were embedded in $10 \%$ formaldehyde-buffered solution, mounted in paraffin blocks, cut in $5 \mu \mathrm{m}$ slices, and stained with HE. The pathological changes of samples were observed and photographed under an optical microscope and scored according to the NAFLD activity score (NAS) [35] for the degrees of steatosis (0-3), lobular inflammation (0-3), and hepatocellular ballooning (0-2). 


\section{Cellular Physiology Cell Physiol Biochem 2018;50:679-693 \begin{tabular}{ll|l} 
DOI: 10.1159/000494235 & $\begin{array}{l}\text { O } 2018 \text { The Author(s). Published by S. Karger AG, Basel } \\
\text { www.karger.com/cpb }\end{array}$
\end{tabular}

Yao et al.: GLP-1 Suppresses miR-19b in Cholesterol Homeostasis

\section{Immunohistochemistry (IHC)}

Rat livers were fixed in 4\% paraformaldehyde, embedded in paraffin, and cut into $4-\mu \mathrm{m}$ sections. After deparaffinization, the sections were boiled in citrate buffer ( $\mathrm{pH}$ 6.0) for $5 \mathrm{~min}$, treated with 3\% hydrogen peroxide for $5 \mathrm{~min}$ to endogenous peroxidase activity, then incubated for $5 \mathrm{~min}$ in Tris buffer (pH 7.6). They were incubated with a monoclonal antibody for ABCA1 (1:200, ab18180) (Abcam, USA) followed by antirabbit IgG antibody (1:2000, ab16891) (Abcam, USA) according to the manufacturer's protocol.

\section{Statistics}

The data were obtained from three independent experiments, presented as the mean \pm standard deviation (SD), and analyzed using SPSS version 20.0 (SPSS Inc, Chicago, IL, USA). To compare the significance of two groups, Student's t test was performed. A $p<0.05$ value was considered statistically significant.

\section{Results}

GLP-1 ameliorates metabolic characteristics and inflammatory markers in SpragueDawley (SD) rats on a high-fat diet

Sixteen weeks after starting the diet treatments, the body weight, liver wet weight, and liver index were increased in the high-fat diet group (HFD) compared to the control diet group (Control). Rats treated with GLP-1 showed a decrease in body weight, liver wet weight, and liver index, both in the normal diet combined with GLP-1 injection group (GLP1) and the high-fat diet combined with GLP-1 injection group (HG) (Fig. 1A, B and C). After 16 weeks of the high-fat diet, ALT and AST as indicators of liver function were increased in HFD group compared to Control group. After 12 weeks of GLP-1 injection, ALT and AST were improved in the HG group compared to the HFD group. However, no difference in ALT and AST were observed between the Control group and GLP-1 group (Fig. 1D). The HFD group demonstrated significant increases in TC and TG compared to the Control group, and the treatment with GLP-1 decreased TC in both the GLP-1 group and the HG group. Meanwhile, GLP-1 injection decreased of TG in the HG group compared to the HFD group, but there was no difference between the Control group and GLP-1 group (Fig. 1E). Serum TNF- $\alpha$ and IL-6 were increased significantly in the HFD group compared to the Control, and GLP-1 treatment decreased them in the HG group compared to HFD group. While, no significant differences between the Control group and the GLP-1 group (Fig. 1F and G). Hepatic histological evaluation showed that the HFD group exhibited steatosis, lobular inflammation, and hepatocellular ballooning. After 12 weeks of GLP-1 injection, NAS was improved in the HG group compared to HFD group. No evidence of hepatic steatosis was observed in the rats fed a regular diet without (Control group) or with GLP-1 (GLP-1 group, Fig. 1H and I). These results reveal that the high-fat diet caused metabolic and inflammatory disorders in SD rats, and GLP-1 significantly improved these imbalances.

The toxicity of cholesterol accumulation and the effect of GLP-1 treatment on cell apoptosis and cholesterol homeostasis

To evaluate the toxic effect of cholesterol accumulation on HepG2 cells, the cells were incubated with different concentrations of cholesterol $(2.5,5.0$, or $10.0 \mathrm{mmol} / \mathrm{L})$ for $24 \mathrm{~h}$. With the increase of cholesterol concentration, the cell viability gradually decreased (Fig. 2A). To detect the therapeutic and protective effects of GLP-1 on cells suffering from lipotoxicity, the HepG2 cells were incubated with or without GLP-1, or exposed to $5 \mathrm{mmol} / \mathrm{L}$ cholesterol with or without GLP-1. We found that cell viability was substantially increased after GLP1 treatment, suggesting that GLP-1 was effective to overcome the toxicity of cholesterol accumulation (Fig. 2B). We further explored the potential impact of cholesterol accumulation and GLP-1 treatment on the apoptosis of HepG2 cells by analysis of caspase-3 activity. The relative activity of caspase- 3 was significantly increased in the cholesterol group compared to the negative control, but this activity was markedly reduced by co-incubation with $5 \mathrm{mmol} / \mathrm{L}$ cholesterol and $10 \mathrm{nmol} / \mathrm{L}$ GLP-1 for $24 \mathrm{~h}$. There was no statistically significant difference 


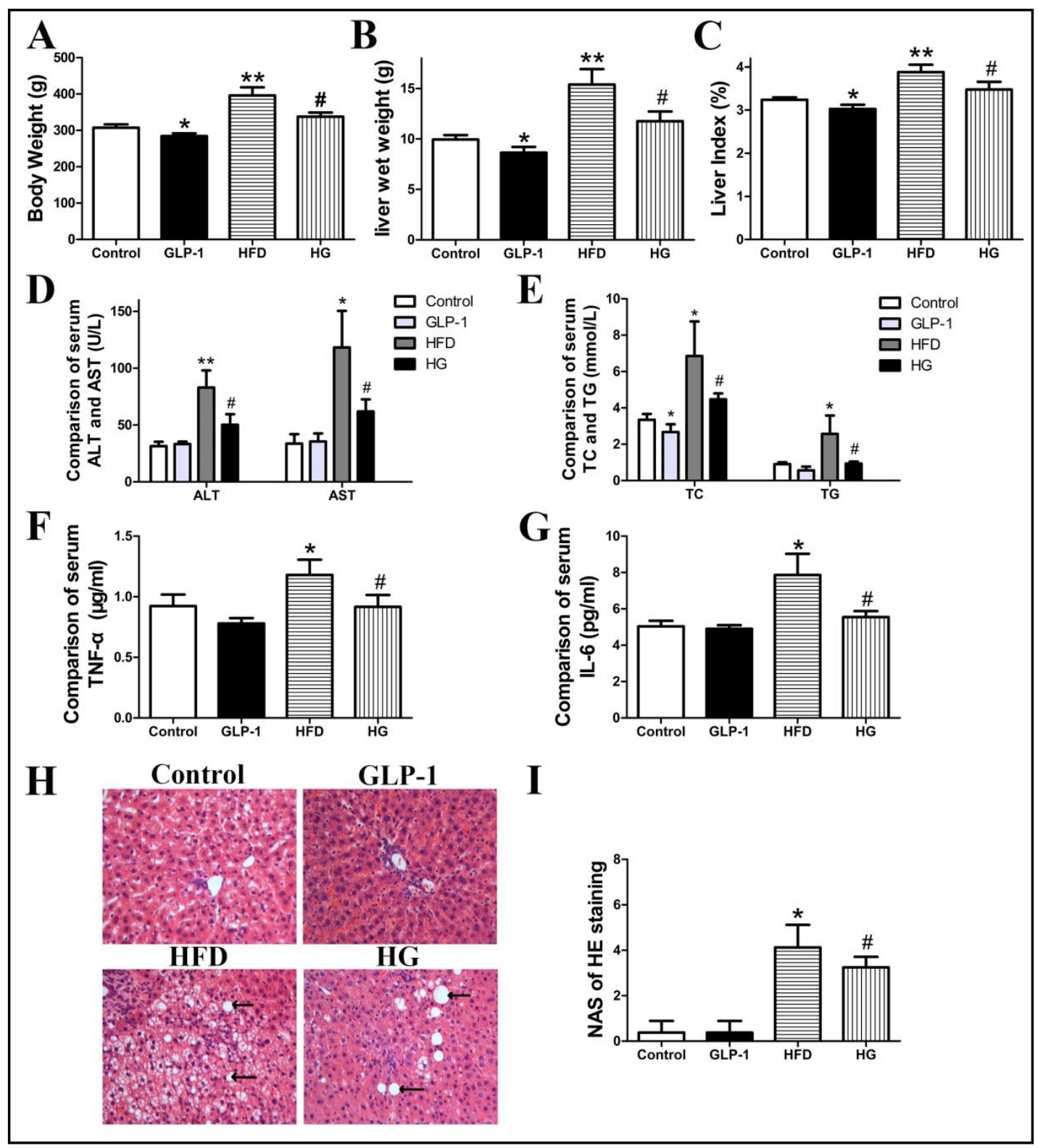

Fig. 1. GLP-1 ameliorates metabolic characteristics and inflammatory markers of SD rats. (A). The body weight of rats for 16 weeks. (B). The liver wet weight of rats for 16 weeks. (C). The liver index of rats for 16 weeks. (D). Comparison of serum ALT and AST levels for 16 weeks. (E). Comparison of serum TC and TG levels for 16 weeks. (F). Comparison of serum TNF- $\alpha$ levels. (G). Comparison of serum IL-6 levels. (H). HE staining of liver sections. Representative photomicrographs $(\times 200)$ are shown for each group. Arrows points out the hepatocellular ballooning in HE staining. (I). The pathological changes of livers were scored according to the NAS. The data are shown as the mean \pm SD $(n=10) .{ }^{*} p<0.05,{ }^{* *} p<0.01$ compared to control group, \#p<0.05 compared to HFD group.

between the control group and GLP-1 group, although the activity of caspase-3 was slightly lower after treatment with GLP-1 (Fig. 2C). HepG2 cells treated with GLP-1 decreased the relative expression of intracellular cholesterol than the control group. In addition, treatment with cholesterol led to a marked increase in cellular cholesterol concentration. Compared with these in cholesterol-treated cells, intracellular cholesterol was decreased when HepG2 cells were treated with GLP-1 and cholesterol (Fig. 2D). There was a negative association between cellular cholesterol efflux and lipid accumulation. BODIPY-Cholesterol provides an 
efficient and sensitive probe for ABCA1-mediated efflux. In our study, the BODIPY-Cholesterol efflux assay indicated that treatment with both cholesterol and GLP-1 significantly increased cholesterol efflux compared to cholesterol only. In the control diet group, GLP-1 showed the same effect (Fig. 2E). Moreover, we observed a large quantity of red lipid droplets in the HepG2 cells in the high-cholesterol group, whereas after the high cholesterol group was treated with GLP-1, the cells displayed a significant reduction in the number of visible droplets. However, almost no lipid droplets were detected in the HepG2 cells in the negative control and GLP-1 groups (Fig. 2F). These results demonstrate that GLP-1 improves apoptosis and cholesterol homeostasis in HepG2 cells.

\section{The effect of GLP-1 treatment on ABCA1 and miR-19b expression}

The effect of GLP-1 on ABCA1 expression in SD rat livers and HepG2 cells was determined by quantitative PCR and western blotting. The mRNA expression of ABCA1 was significantly enhanced in GLP-1-treated tissue and cells compared to the untreated control group (Fig. 3A and $\mathrm{B}$ ). This increase in mRNA expression was also associated with a concomitant increase

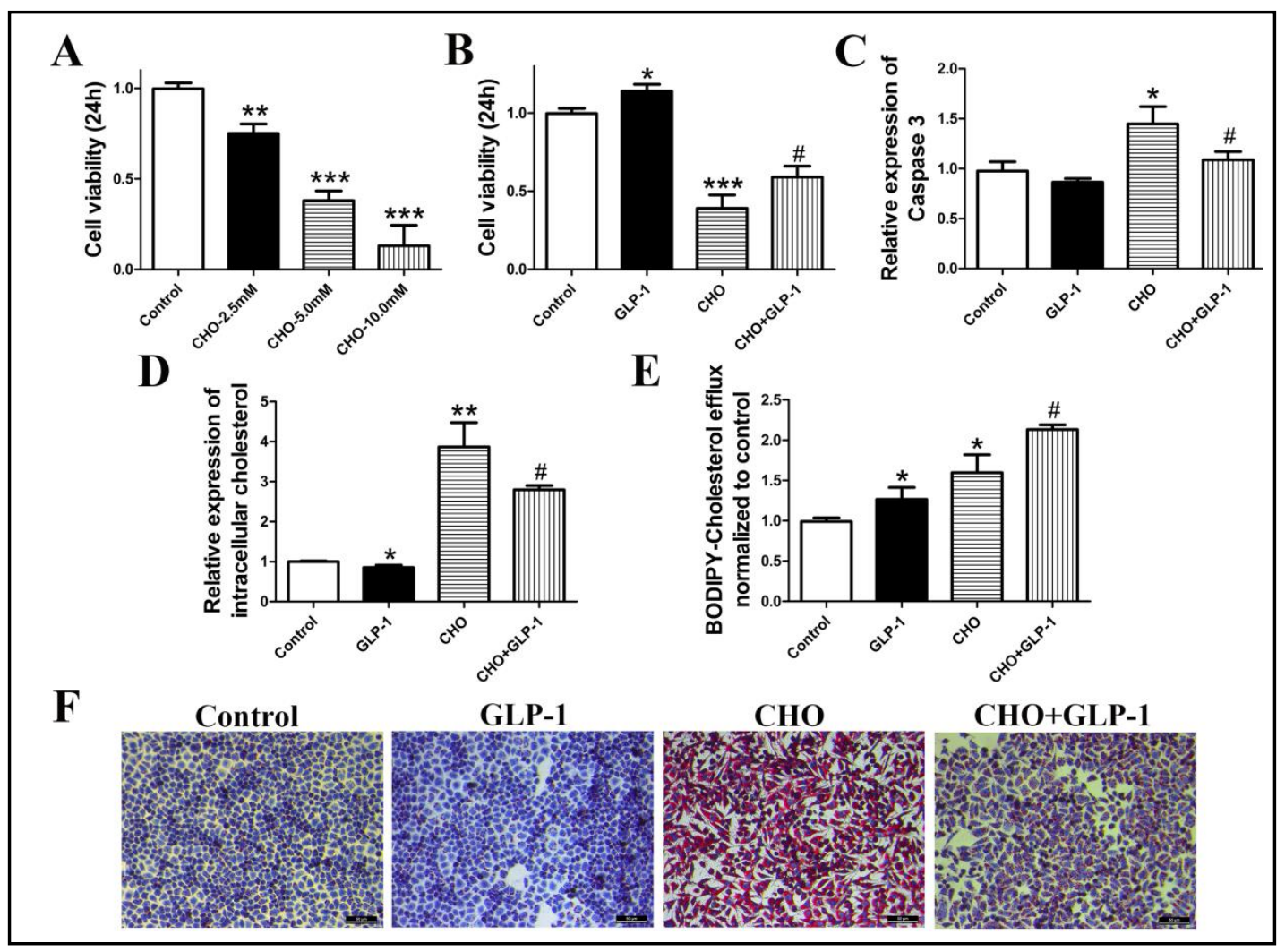

Fig. 2. The toxicity of cholesterol accumulation and the effect of GLP-1 treatment on cell apoptosis and cholesterol homeostasis. (A). HepG2 cells were treated with 2.5, 5.0 or $10.0 \mathrm{mmol} / \mathrm{L}$ cholesterol for $24 \mathrm{~h}$, and cell viability was detected by CCK-8 assay. (B). The cells were incubated with or without GLP-1, and exposed to $5 \mathrm{mmol} / \mathrm{L}$ cholesterol with or without GLP-1. Then, cell viability was detected by CCK-8 assay. (C). The cells were incubated with or without GLP-1, and exposed to $5 \mathrm{mmol} / \mathrm{L}$ cholesterol with or without GLP-1 before determine the relative activation of caspase 3. (D). The cells were incubated with or without GLP-1, and exposed to $5 \mathrm{mmol} / \mathrm{L}$ cholesterol with or without GLP-1 before examine the relative expression of intracellular cholesterol. (E). The cells were incubated with or without GLP-1, and exposed to $5 \mathrm{mmol} / \mathrm{L}$ cholesterol with or without GLP-1 before measured BODIPY-Cholesterol efflux. (F). The cells were incubated with or without GLP-1, and exposed to $5 \mathrm{mmol} / \mathrm{L}$ cholesterol with or without GLP-1 before stained with oil red 0 . Representative photomicrographs $(\times 200)$ are shown for each group. The data are shown as mean $\pm \mathrm{SD}(\mathrm{n}=3)^{*} \mathrm{p}<0.05,{ }^{* *} \mathrm{p}<0.01,{ }^{* * *} \mathrm{p}<0.001$ compared to control group, $\# \mathrm{p}<0.05$ compared to CHO group. 


\section{Cellular Physiology Cell Physiol Biochem 2018;50:679-693 \begin{tabular}{l|l|l} 
DOI: 10.1159/000494235 & $\begin{array}{l}\text { O 2018 The Author(s). Published by S. Karger AG, Basel } \\
\text { www.karger.com/cpb }\end{array}$ \\
\hline
\end{tabular}

in the corresponding protein levels. A significant increase in ABCA1 protein was observed following GLP-1 treatment compared to the untreated control levels. However, the expression of peroxisome proliferator-activated receptor $\alpha$ (PPAR- $\alpha$ ), the main transcriptional regulator of ABCA1 gene [36], was not altered in GLP-1-treated groups (Fig. 3C and D). These results suggested a potent regulatory role for GLP-1 in ABCA1 expression in vivo and in vitro. To investigate the relationship between GLP-1 and miR-19b, the changes in the expression of miR-19b were assessed by quantitative PCR. It has been reported that miR-19b dramatically represses ABCA1 expression through partial complementary binding to the 3'-UTR of ABCA1 mRNA [27]. To investigate whether miR-19b was involved in GLP-1-induced ABCA1 expression, we examined miR-19b levels in rat livers and HepG2 cells. As shown in Fig. 3E-H, GLP-1 significantly decreased miR-19b in vivo and in vitro. To detect the functional role of miR-19b in the effects of GLP- 1 on ABCA1 expression, we further carried out the study under the condition of the gain or loss of functions of miR-19b. The data of this study proved that GLP-1 regulates the expression of genes and miRNAs related to cholesterol homeostasis.

The regulation of $A B C A 1$ expression and cholesterol homeostasis by miR-19b

To further investigate the interplay between GLP-1, miR-19b and ABCA1, miR-19b inhibition and overexpression experiments were done to explore the effects of GLP-1mediated reduction in miR-19b on the mediator of cholesterol transport: ABCA1. As shown in Fig. 4A and B, the HG-Ant group had a significant increase compared with the HG group in both ABCA1 mRNA and protein. Similarly, the HFD and HG-Ago groups showed a significant reduction in ABCA1 expression. The same alterations were also observed in immunohistochemical staining of ABCA1. ABCA1 expression was enhanced in rats treated with GLP-1 injection, namely the GLP-1 group and HG group. Expression of ABCA1 trended to further increase in rats treated with GLP-1 together with antagomiR-19b, and significantly decreased in the GLP-1+agomiR-19b-treated rats when compared with the HG group (Fig. 4C). To manipulate the expression of miR-19b in HepG2 cells, a miR-19b mimics (40nM), a miR-19b inhibitor $(100 \mathrm{nM})$ and a negative control (miRNA-NC-FAM) were used for transfection. Flow cytometry indicated that the transfection efficiency reached about $80 \%$ in the cells (Fig. 4D and E). After transfected with miR-19b mimics, HepG2 cell viability was decreased and cell apoptosis was increased compared to the CHO+mimics-NC group. On the contrary, transfecting miR-19b inhibitor facilitated cell viability and inhibited cell apoptosis compared to the $\mathrm{CHO}+$ inhibitor-NC group. (Figure $4 \mathrm{~F}$ and G). As shown in Figure $5 \mathrm{~A}$ and $B$, exposure of HepG2 cells to miR-19b-inhibitor resulted in a significant increase in both the expression of ABCA1 mRNA and protein. In contrast, HepG2 cells exposed to miR-19bmimics showed a significant reduction in ABCA1 expression. Taken together, these findings reveal that GLP-1 regulates ABCA1 expression by inhibiting the level of miR-19b. As shown in Figure 5C, exposing the HepG2 cells to the miR-19b-inhibitor resulted in a significant reduction in intracellular cholesterol measurement. In contrast, the HepG2 cells that were exposed to miR-19b-mimics showed a significant increase. The Oil red 0 staining and cholesterol measurement showed similar results (Figure 5D). Additionally, the miR-19binhibitor group significantly increased cholesterol efflux compared to the miR-19b-inhibitor negative control (Scrambled) group, and the miR-19b-mimics group showed the opposite results (Figure 5E). These results demonstrate that miR-19b regulates ABCA1 expression and cholesterol homeostasis in vivo and in vitro. 


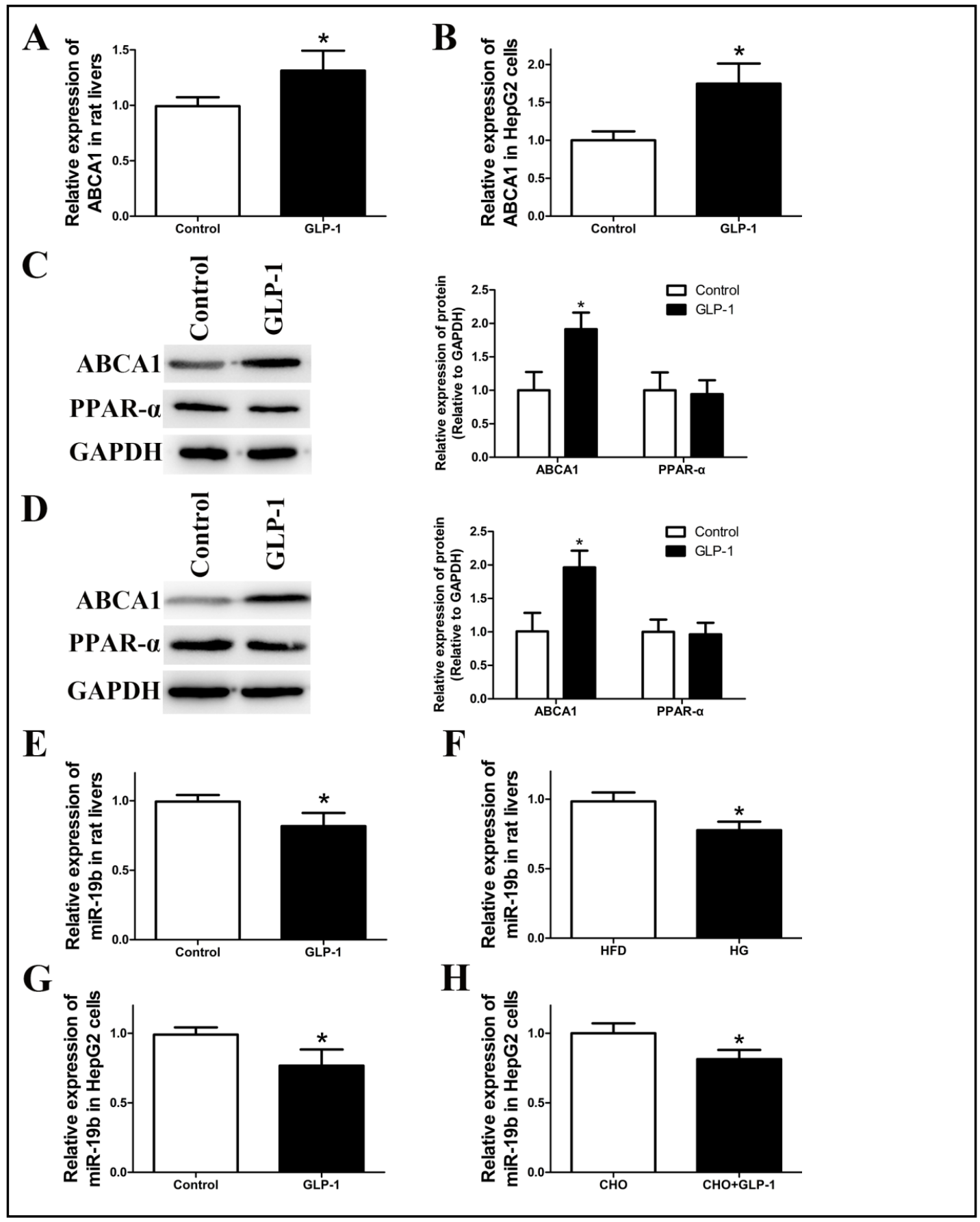

Fig. 3. The effect of GLP-1 treatment on ABCA1 and miR-19b expression. (A). The relative expression of ABCA1 mRNA after $20 \mu \mathrm{g} / \mathrm{kg}$ GLP-1 injection for 12 weeks in control diet-fed rats. (B). The relative expression of ABCA1 mRNA after treatment with or without $10 \mathrm{nmol} / \mathrm{L} \mathrm{GLP}-1$ for $24 \mathrm{~h}$. (C). The expression of ABCA1 and PPAR- $\alpha$ protein after $20 \mu \mathrm{g} / \mathrm{kg}$ GLP-1 injection for 12 weeks in control diet-fed rats. (D). The expression of ABCA1 and PPAR- $\alpha$ protein after treatment with or without $10 \mathrm{nmol} / \mathrm{L}$ GLP-1 for $24 \mathrm{~h}$. (E). The relative expression of miR-19b mRNA after $20 \mu \mathrm{g} / \mathrm{kg}$ GLP-1 injection for 12 weeks in control diet-fed rats. (F). The relative expression of miR-19b mRNA after $20 \mu \mathrm{g} / \mathrm{kg}$ GLP-1 injection for 12 weeks in high fat dietfed rats. (G). The relative expression of miR-19b mRNA after treatment with or without $10 \mathrm{nmol} / \mathrm{L}$ GLP-1 for $24 \mathrm{~h}$. (H). The relative expression of miR-19b mRNA after treatment with or without $10 \mathrm{nmol} / \mathrm{L}$ GLP-1 in the presence of $5 \mathrm{mmol} / \mathrm{L}$ cholesterol for $24 \mathrm{~h}$. The data are shown as mean $\pm \mathrm{SD}(\mathrm{A}, \mathrm{C}, \mathrm{E}$ and $\mathrm{F}, \mathrm{n}=10, \mathrm{~B}, \mathrm{D}$, $\mathrm{G}$ and $\mathrm{H}, \mathrm{n}=3$ ). ${ }^{*} \mathrm{p}<0.05$ compared to control group. 


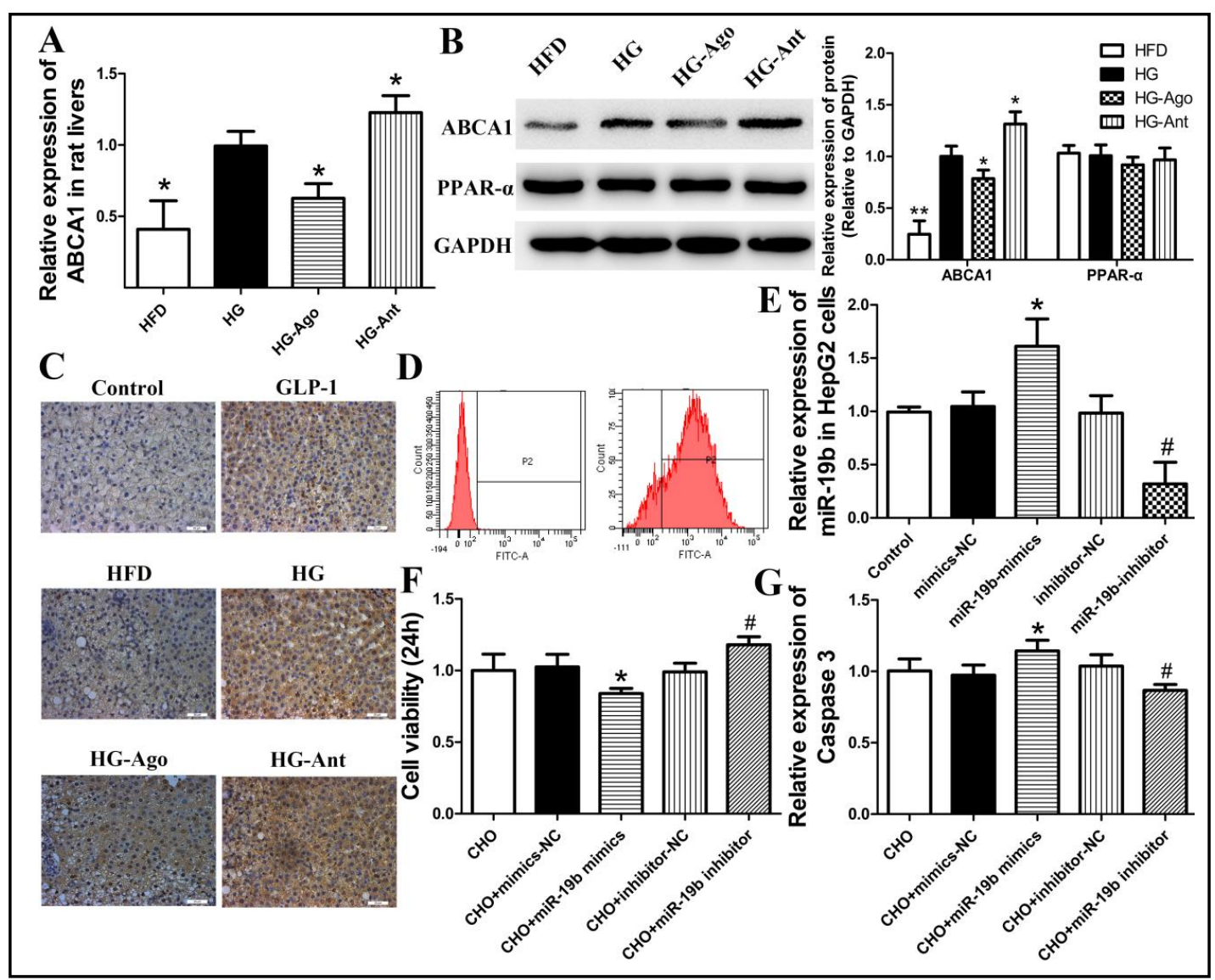

Fig. 4. The regulation of $A B C A 1$ expression and cholesterol homeostasis by miR-19b. (A). The relative expression of ABCA1 mRNA in high-fat diet alone (HFD), HFD+GLP-1 (HG), HFD+GLP-1+agomiR-19b (HG-Ago), and HFD+GLP-1+antagomiR-19b group (HG-Ant). (B). The expression of ABCA1 and PPAR- $\alpha$ protein in high-fat diet alone (HFD), HFD+GLP-1 (HG), HFD+GLP-1+agomiR-19b (HG-Ago), and HFD+GLP1+antagomiR-19b group (HG-Ant). (C). The immunohistochemical staining of ABCA1 of rat liver slices. (D). The transfection efficiency was detected by flow cytometry. (E). The relative expression of miR-19b was measured after transfection by real-time quantitative PCR. (F). The cells transfected with mimics-NC, miR19b mimics, inhibitor-NC or miR-19b inhibitor were incubated with $5.0 \mathrm{mmol} / \mathrm{L}$ cholesterol. The relative cell viability was detected by CCK-8. (G). The cells transfected with mimics-NC, miR-19b mimics, inhibitorNC or miR-19b inhibitor were incubated with $5.0 \mathrm{mmol} / \mathrm{L}$ cholesterol. The relative activation of caspase 3 was detected. The data are shown as mean $\pm \mathrm{SD}$. (A-C, $\mathrm{n}=10, \mathrm{D}-\mathrm{G}, \mathrm{n}=3) \mathrm{E}:{ }^{*} p<0.05$ compared to mimics-NC group, $\# p<0.05$ compared to inhibitor-NC group; $\mathrm{F}$ and $\mathrm{G}:{ }^{*} p<0.05$ compared to $\mathrm{CHO}+$ mimics-NC group, $\# p<0.05$ compared to $\mathrm{CHO}+$ inhibitor-NC group. 


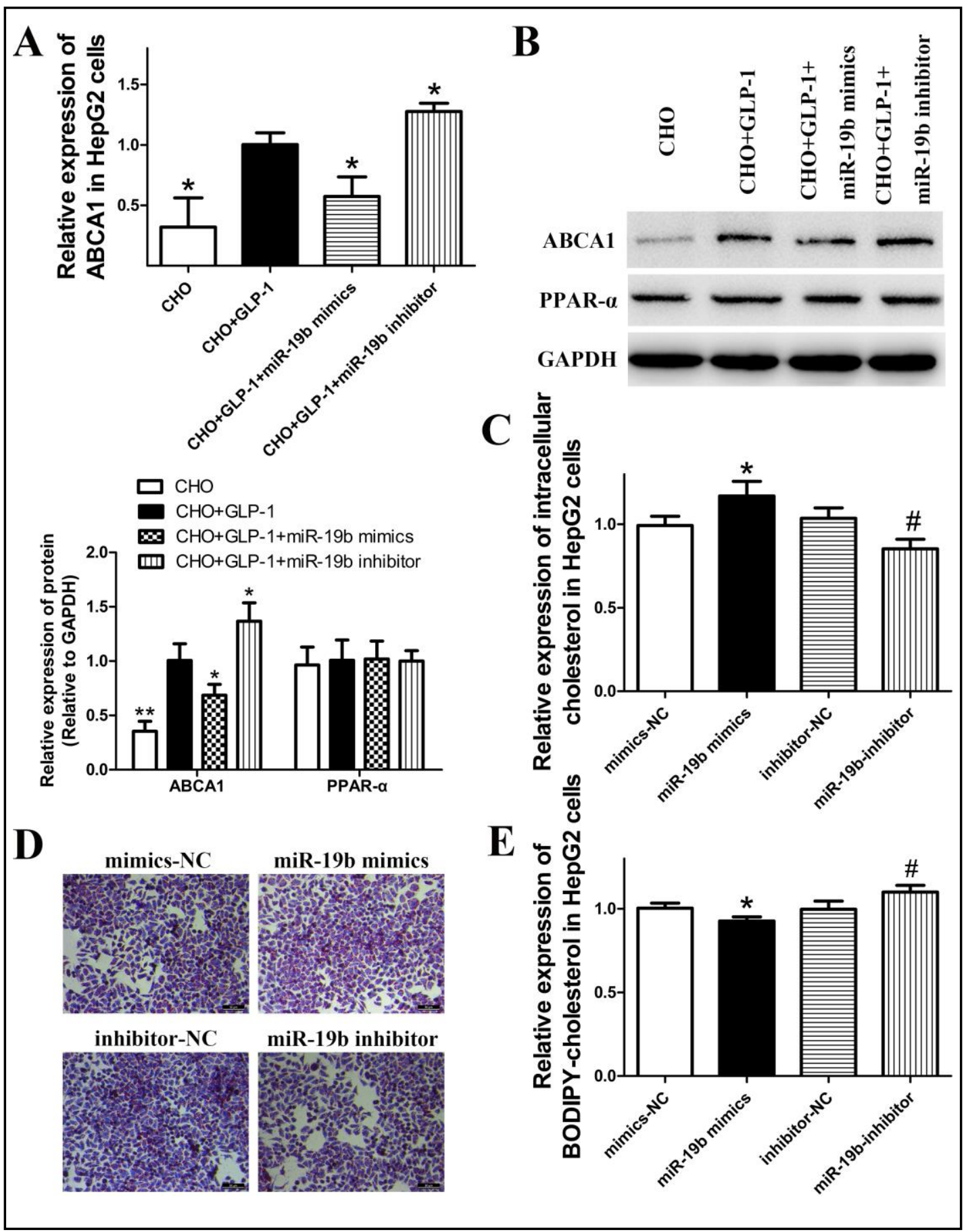

Fig. 5. (A). The relative expression of ABCA1 mRNA was analyzed after overexpression and inhibition of miR$19 \mathrm{~b}$ by transfection. (B). The expression of ABCA1 and PPAR- $\alpha$ protein were analyzed after overexpression and inhibition of miR-19b by transfection. (C). The relative expression of intracellular cholesterol in HepG2 cells. (D). The HepG2 cells were stained with oil red O. (E). Relative expression of BODIPY-cholesterol in HepG2 cells. The data are shown as mean \pm SD. (A-E, $n=3$ ) C and E: ${ }^{*} p<0.05$ compared to mimics-NC group, $\# p<0.05$ compared to inhibitor-NC group. 


\section{Discussion}

T2DM as a metabolic disease, is usually accompanied by abnormal lipid metabolism. The toxicity of cholesterol enriches the connotation of lipotoxicity, which contributes to the development of T2DM $[37,38]$. GLP-1 as a promising anti-diabetic drug, could improve lipid accumulation and inflammation in hepatocytes $[19,20,39]$. However, the mechanism of this effect is poorly understood. In this study, we investigated the protective effect and the molecular mechanisms underlying GLP-1's effects on cholesterol homeostasis in HepG2 cells and high-fat diet rats. As illustrated in Fig. 4 and 5, GLP-1 up-regulated ABCA1 by suppressing miR-19b and induced ABCA1-dependent cholesterol efflux from HepG2 cells, resulting in the reduction in cholesterol deposition.

Because of the key role played by GLP-1 in mediating lipid metabolism, much researches has aimed to understand the cellular and molecular mechanisms involved [18, 19, 40]. Fat accumulation in the liver is regarded as a key pathogenic factor of metabolic diseases. Highfat diet resulting in weight gain is associated with increased liver weight and liver index. It was reported that administration of GLP-1 reversed hepatic steatosis in an obese mouse model $[41,42]$. In this study, the rats gained weight and showed dyslipidaemia on the high-fat diet, while after GLP-1 treatment for 12 weeks, their weight and liver index were improved. Our data from this study also indicate that, persistent improvement in ALT, AST, TC and TG were observed in the HG group compared to the HFD group. Our histopathological findings demonstrate the damage of the high-fat diet to the liver structure, with many lipid droplets in hepatocytes, while GLP-1 injection reversed this phenomenon. TNF- $\alpha$ and IL6 , two cytokines are involved in the pathology of diseases, were involved in the toxicity of cholesterol accumulation and in the improvement caused by GLP-1 treatment.

Hao et al. established a cholesterol overload model by incubating pancreatic $\beta$-cells with $10 \mathrm{mmol} / \mathrm{L}$ soluble cholesterol [43]. HepG2 cells were treated with $5 \mathrm{mmol} / \mathrm{L}$ soluble cholesterol, which was higher than normal culture medium, and this did not lead to more rapid cell death or damage than $10 \mathrm{mmol} / \mathrm{L}$ cholesterol. Our results suggest that redundant intracellular cholesterol inhibited hepatic cell viability, and disturbed the internal and external balance of cholesterol in vitro. Caspase-3, a marker of cell apoptosis, was involved in the toxicity of cholesterol. GLP-1 treatment significantly improved the cell viability and moderated cholesterol metabolism in numerous ways. The results are consistent with previous studies on SD rats. Thus, our findings may help explain the improved lipid profile seen in patients receiving GLP-1 treatment.

However, it is not clear that how ABCA1 expression is responsive to GLP-1 in hepatic cells. MiRNAs regulate gene expression post-transcriptionally by binding to 3'-UTRs and repress protein production by destabilizing the mRNA or by translational silencing [24, 25]. MiR-19b potently inhibits ABCA1 expression by binding to the 3'-UTR of ABCA1 mRNA [29]. ABCA1 is important in HDL particle assembly at the surface of the hepatocyte [44]. Based on this, we measured the role of miR-19b in GLP-1-induced ABCA1 expression. Our observation that GLP-1 decreased miR-19b and enhanced ABCA1 mRNA and protein levels suggests that the peptide regulates cholesterol homeostasis in multiple ways. PPAR- $\alpha$, an important transcriptional regulator of genes involved in lipid metabolism [45, 46], was not affected by GLP-1, suggesting that PPAR- $\alpha$ expression cannot account for the alteration of ABCA1 with GLP-1 treatment.

Subsequently, we explored the impact of miR-19b knockdown and overexpression on ABCA1 expression in hepatocytes. GLP-1 increased the expression of ABCA1 by suppressing miR-19b in vivo and in vitro, then accelerated cholesterol efflux and improved lipid metabolism. Consistent with these results, hepatic lipid deposition dramatically decreased in rats treated with GLP-1 or GLP-1 together with antagomiR-19b. Our findings further demonstrate the regulatory effect of GLP-1 is intimately associated with its role in modulating ABCA1 expression and cholesterol homeostasis in hepatocytes. All these mechanisms contribute to the action of GLP-1. 


\section{Cellular Physiology Cell Physiol Biochem 2018;50:679-693 \begin{tabular}{l|l} 
DOI: 10.1159/000494235 & $\begin{array}{l}\text { O } 2018 \text { The Author(s). Published by S. Karger AG, Basel } \\
\text { www.karger.com/cpb }\end{array}$
\end{tabular}

Although cholesterol is an important component of most cells, its inappropriate accumulation leads to diabetes, obesity, atherosclerosis and cancers [47-50]. GLP-1 has particularly strong effects in regulating lipid metabolism [51, 52]. However, the molecular mechanism linking the two is largely missing. Our earlier results in rats' experiments led us to further anticipate the mechanism underlying the molecular link between GLP-1 and cholesterol homeostasis. In this study, we demonstrated that GLP-1 affects cholesterol homeostasis by regulating the expression of miR-19b and ABCA1. Our data point to miR-19b as an upstream regulator of the transcriptional network involved in lipid mechanism and suggest antagomiR-19b could treat dyslipidaemia by the view of increasing the expression of ABCA1. In summary, our findings provide mechanistic evidence that therapeutic intervention with GLP-1 decreases hypercholesterolaemia-associated impairment, possibly by regulating miR-19b level, which in turn enhances ABCA1 expression, thus shedding more light on potential novel therapeutic approaches to reverse lipid mechanism disorders. However, our understanding of the relationship between miR-19b and GLP-1 is still at an early stage. A better understanding of the mechanisms whereby miR-19b regulates lipid metabolism by targeting different signalling pathways may enable the development of miR-19b-mediated therapy.

\section{Acknowledgements}

This study was supported by National Natural Science Foundation of China (No. 81370902, No. 81170744), Foundation of Key Laboratory of Myocardial Ischemia, Ministry of Education (No. KF201810), Postgraduate innovative research project of Harbin Medical University (No. YJSCX2016-21HYD).

\section{Disclosure Statement}

The authors declare that they have no competing interests.

\section{References}

1 Stern MP: Diabetes and cardiovascular disease. The "common soil" hypothesis. 1995;44:369-374.

-2 Moller DE, Kaufman KD: Metabolic syndrome: a clinical and molecular perspective. Annu Rev Med 2005;56:45-62.

-3 Henkel J, Coleman CD, Schraplau A, Jöhrens K, Weber D, Castro JP, Hugo M, Schulz TJ, Krämer S, Schürmann A, Püschel GP: Induction of steatohepatitis (NASH) with insulin resistance in wildtype B6 mice by a western-type diet containing soybean oil and cholesterol. Mol Med 2017;23:70-82.

4 Maxfield FR, Tabas I: Role of cholesterol and lipid organization in disease. Nature 2005;438:612-621.

5 Goedeke L, Fernández-Hernando C: Regulation of cholesterol homeostasis. Cell Mol Life Sci 2012;69:915930.

6 Oram JF, Lawn RM: ABCA1. The gatekeeper for eliminating excess tissue cholesterol. J Lipid Res 2001;42:1173-1179.

7 Brunham LR, Kruit JK, Verchere CB, Hayden MR: Cholesterol in islet dysfunction and type 2 diabetes. J Clin Invest 2008;118:403-408.

-8 Jiang T, Ren K, Chen Q Li H, Yao R, Hu H, Lv YC, Zhao GJ: Leonurine prevents atherosclerosis via promoting the expression of ABCA1 and ABCG1 in a Ppary/Lxr signaling pathway-dependent manner. Cell Physiol Biochem 2017;43:1703-1717.

-9 Phillips MC: Molecular mechanisms of cellular cholesterol efflux. J Biol Chem 2014;289:24020-24029.

10 Oram JF, Heinecke JW: ATP-binding cassette transporter A1: a cell cholesterol exporter that protects against cardiovascular disease. Physiol Rev 2005;85:1343-1372.

11 Zannis VI, Chroni A, Krieger M: Role of apoA-I, ABCA1, LCAT, and SR-BI in the biogenesis of HDL. J Mol Med 2006;84:276-294. 


\section{Cellular Physiology Cell Physiol Biochem 2018;50:679-693 \begin{tabular}{l|l|l} 
and Biochemistry & DOI: 10.1159/000494235 & $\begin{array}{l}\text { C } 2018 \text { The Author(s). Published by S. Karger AG, Basel } \\
\text { www.karger.com/cpb }\end{array}$
\end{tabular}

12 Ikonen E: Mechanisms for cellular cholesterol transport: defects and human disease. Physiol Rev 2006;86:1237-1261.

13 Zhang F, Du G: Dysregulated lipid metabolism in cancer. World J Biol Chem 2012;3:167-174.

14 Kim YK, Park JH, Park SH, Lim B, Baek WK, Suh SI, Lim JG, Ryu GR, Song DK: Protective role of glucagonlike peptide-1 against glucosamine-induced cytotoxicity in pancreatic beta cells. Cell Physiol Biochem 2010;25:211-220.

15 Lee YS, Park MS, Choung JS, Kim SS, Oh HH, Choi CS, Ha SY, Kang Y, Kim Y, Jun HS: Glucagon-like peptide-1 inhibits adipose tissue macrophage infiltration and inflammation in an obese mouse model of diabetes. Diabetologia 2012;55:2456-2468.

16 Ben-Shlomo S, Zvibel I, Shnell M, Shlomai A, Chepurko E, Halpern Z, Barzilai N, Oren R, Fishman S: Glucagon-like peptide-1 reduces hepatic lipogenesis via activation of AMP-activated protein kinase. J Hepatol 2011;54:1214-1223.

17 Patel VJ, Joharapurkar AA, Shah GB, Jain MR: Effect of GLP-1 based therapies on diabetic dyslipidemia. Curr Diabetes Rev 2014;10:238-250.

18 Chen J, Zhao H, Ma X, Zhang Y, Lu S, Wang Y, Zong C, Qin D, Wang Y, Yingfeng Yang Y, Wang X, Liu Y: GLP1/GLP-1R signaling in regulation of adipocyte differentiation and lipogenesis. Cell Physiol Biochem 2017;42:1165-1176.

19 Liao P, Yang D, Liu D, Zheng Y: GLP-1 and Ghrelin Attenuate High Glucose/High Lipid-Induced Apoptosis and Senescence of Human Microvascular Endothelial Cells. Cell Physiol Biochem 2017;44:1842-1855.

-20 Chehade JM, Alcalde R, Naem E, Mooradian AD, Wong NC, Haas MJ: Induction of apolipoprotein A-I gene expression by glucagon-like peptide- 1 and exendin- 4 in hepatocytes but not intestinal cells. Metabolism 2013;62:265-274.

-21 Yin QH, Zhang R, Li L, Wang YT, Liu JP, Zhang J, Bai L, Cheng JQ, Fu P, Liu F: Exendin-4 ameliorates lipotoxicity-induced glomerular endothelial cell injury by improving ABC transporter A1-mediated cholesterol efflux in diabetic apoE knockout mice. J Biol Chem 2016;291:26487-26501.

-22 Li J, Murao K, Imachi H, Masugata H, Iwama H, Tada S, Zhang GX, Kobayashi R, Ishida T, Tokumitsu $\mathrm{H}$ : Exendin-4 regulates pancreatic ABCA1 transcription via CaMKK/CaMKIV pathway. J Cell Mol Med 2010;14:1083-1087.

23 Mostafa AM, Hamdy NM, El-Mesallamy HO, Abdel-Rahman SZ: Glucagon-like peptide 1 (GLP-1)based therapy upregulates LXR-ABCA1/ABCG1 cascade in adipocytes. Biochem Biophys Res Commun 2015;468:900-905.

-24 Kang MH, Zhang LH, Wijesekara N, de Haan W, Butland S, Bhattacharjee A, Hayden MR: Regulation of ABCA1 protein expression and function in hepatic and pancreatic islet cells by miR-145. Arterioscler Thromb Vasc Biol 2013;33:2724-2732.

25 Schober A, Nazari-Jahantigh M, Weber C: MicroRNA-mediated mechanisms of the cellular stress response in atherosclerosis. Nat Rev Cardiol 2015;12:361-374.

-26 Wijesekara N, Zhang LH, Kang MH, Abraham T, Bhattacharjee A, Warnock GL, Verchere CB, Hayden MR: MiR-33a modulates ABCA1 expression, cholesterol accumulation, and insulin secretion in pancreatic islets. Diabetes 2012;61:653-658.

-27 Shi C, Huang F, Gu X, Zhang M, Wen J, Wang X, You L, Cui X, Ji C, Guo X: Adipogenic miRNA and metasignature miRNAs involved in human adipocyte differentiation and obesity. Oncotarget 2016;7:4083040845.

28 Pirola CJ, Fernández Gianotti T, Castaño GO, Mallardi P, San Martino J, Mora Gonzalez Lopez Ledesma M, Flichman D, Mirshahi F, Sanyal AJ, Sookoian S: Circulating microRNA signature in non-alcoholic fatty liver disease: from serum non-coding RNAs to liver histology and disease pathogenesis. Gut 2015;64:800-812.

29 Lv YC, Tang YY, Peng J, Zhao GJ, Yang J, Yao F, Ouyang XP, He PP, Xie W, Tan YL, Zhang M, Liu D, Tang DP, Cayabyab FS, Zheng XL, Zhang DW, Tian GP, Tang CK: MicroRNA-19b promotes macrophage cholesterol accumulation and aortic atherosclerosis by targeting ATP-binding cassette transporter A1. Atherosclerosis 2014;236:215-226.

-30 Chen C, Cheng P, Xie H, Zhou HD, Wu XP, Liao EY, Luo XH: MiR-503 regulates osteoclastogenesis via targeting RANK. J Bone Miner Res 2014;29:338-347.

-31 Araújo F, Shrestha N, Gomes MJ, Herranz-Blanco B, Liu D, Hirvonen JJ, Granja PL, Santos HA, Sarmento B: In vivo dual-delivery of glucagon like peptide-1 (GLP-1) and dipeptidyl peptidase-4 (DPP4) inhibitor through composites prepared by microfluidics for diabetes therapy. Nanoscale 2016;8:10706-10713. 


\section{Cellular Physiology Cell Physiol Biochem 2018;50:679-693 \begin{tabular}{l|l|l} 
and Biochemistry Published online: 12 October 2018 & $\begin{array}{l}\text { @ } 2018 \text { The Author(s). Published by S. Karger AG, Basel } \\
\text { www.karger.com/cpb }\end{array}$ \\
\hline
\end{tabular}}

Yao et al.: GLP-1 Suppresses miR-19b in Cholesterol Homeostasis

-32 Li X, Wu Q, Bu M, Hu L, Du WW, Jiao C, Pan H, Sdiri M, Wu N, Xie Y, Yang BB: Ergosterol peroxide activates Foxo3-mediated cell death signaling by inhibiting AKT and c-Myc in human hepatocellular carcinoma cells. Oncotarget 2016;7:33948-33959.

-33 Schmittgen TD, Livak KJ: Analyzing real-time PCR data by the comparative C(T) method. Nat Protoc 2008;3:1101-1108.

-34 Sankaranarayanan S, Kellner-Weibel G, de la Llera-Moya M, Phillips MC, Asztalos BF, Bittman R, Rothblat GH: A sensitive assay for ABCA1-mediated cholesterol efflux using BODIPY-cholesterol. J Lipid Res 2011;52:2332-2340.

-35 Kleiner DE, Brunt EM, Van Natta M, Behling C, Contos MJ, Cummings OW, Ferrell LD, Liu YC, Torbenson MS, Unalp-Arida A, Yeh M, McCullough AJ, Sanyal AJ: Nonalcoholic Steatohepatitis Clinical Research Network. Design and validation of a histological scoring system for nonalcoholic fatty liver disease. Hepatology 2005;41:1313-1321.

-36 Schmitz G, Langmann T: Transcriptional regulatory networks in lipid metabolism control ABCA1 expression. Biochim Biophys Acta 2005;1735:1-19.

37 Bays HE, Jones PH, Brown WV, Jacobson TA: National lipid association. National lipid association annual summary of clinical lipidology 2015. J Clin Lipidol 2014;8:S1-36.

-38 Rosenblit PD: Common medications used by patients with type 2 diabetes mellitus: what are their effects on the lipid profile? Cardiovasc Diabetol 2016;15:95.

39 Xu F, Li Z, Zheng X, Liu H, Liang H, Xu H, Chen Z, Zeng K, Weng J: SIRT1 mediates the effect of GLP-1 receptor agonist exenatide on ameliorating hepatic steatosis. Diabetes 2014;63:3637-3646.

40 Mishra AK, Dubey V, Ghosh AR: Obesity: An overview of possible role(s) of gut hormones, lipid sensing and gut microbiota. Metabolism 2016;65:48-65.

41 Tushuizen ME, Bunck MC, Pouwels PJ, van Waesberghe JH, Diamant M, Heine RJ: Incretin mimetics as a novel therapeutic option for hepatic steatosis. Liver Int 2006;26:1015-1017.

$>42$ Astrup A, Rössner S, Van Gaal L, Rissanen A, Niskanen L, Al Hakim M, Madsen J, Rasmussen MF, Lean ME: Effects of liraglutide in the treatment of obesity: a randomised, double-blind, placebo-controlled study. Lancet 2009;374:1606-1616.

-43 Hao M, Head WS, Gunawardana SC, Hasty AH, Piston DW: Direct effect of cholesterol on insulin secretion: a novel mechanism for pancreatic beta-cell dysfunction. Diabetes 2007;56:2328-2338.

44 Vedhachalam C, Duong PT, Nickel M, Nguyen D, Dhanasekaran P, Saito H, Rothblat GH, Lund-Katz S, Phillips MC: Mechanism of ATP-binding cassette transporter A1-mediated cellular lipid efflux to apolipoprotein A-I and formation of high density lipoprotein particles. J Biol Chem 2007;282:25123-25130.

45 Khera AV, Millar JS, Ruotolo G, Wang MD, Rader DJ: Potent peroxisome proliferator-activated receptor- $\alpha$ agonist treatment increases cholesterol efflux capacity in humans with the metabolic syndrome. Eur Heart J 2015;36:3020-3022.

-46 van Diepen JA, Jansen PA, Ballak DB, Hijmans A, Hooiveld GJ, Rommelaere S, Galland F, Naquet P, Rutjes FP, Mensink RP, Schrauwen P, Tack CJ, Netea MG, Kersten S, Schalkwijk J, Stienstra R: PPAR-alpha dependent regulation of vanin-1 mediates hepatic lipid metabolism. J Hepatology 2014;61:366-372.

-47 Van Rooyen DM, Larter CZ, Haigh WG, Yeh MM, Ioannou G, Kuver R, Lee SP, Teoh NC, Farrell GC: Hepatic free cholesterol accumulates in obese, diabetic mice and causes nonalcoholic steatohepatitis. Gastroenterology 2011;141:1393-1403.

48 Glass CK, Witztum JL: Atherosclerosis. the road ahead. Cell 2001;104:503-516.

49 Reeves GK, Pirie K, Beral V, Green J, Spencer E, Bull D: Million women study collaboration. Cancer incidence and mortality in relation to body mass index in the million women study: cohort study. BMJ 2007;335:1134.

50 Renehan AG, Tyson M, Egger M, Heller RF, Zwahlen M: Body-mass index and incidence of cancer: a systematic review and meta-analysis of prospective observational studies. Lancet 2008;371:569-578.

51 Miyazaki M, Kato M, Tanaka K, Tanaka M, Kohjima M, Nakamura K, Enjoji M, Nakamuta M, Kotoh K, Takayanagi R: Increased hepatic expression of dipeptidyl peptidase-4 in non-alcoholic fatty liver disease and its association with insulin resistance and glucose metabolism. Mol Med Rep 2012;5:729-733.

-52 Kahn BB, Alquier T, Carling D, Hardie DG: AMP-activated protein kinase: ancient energy gauge provides clues to modern understanding of metabolism. Cell Metab 2005;1:15-25. 